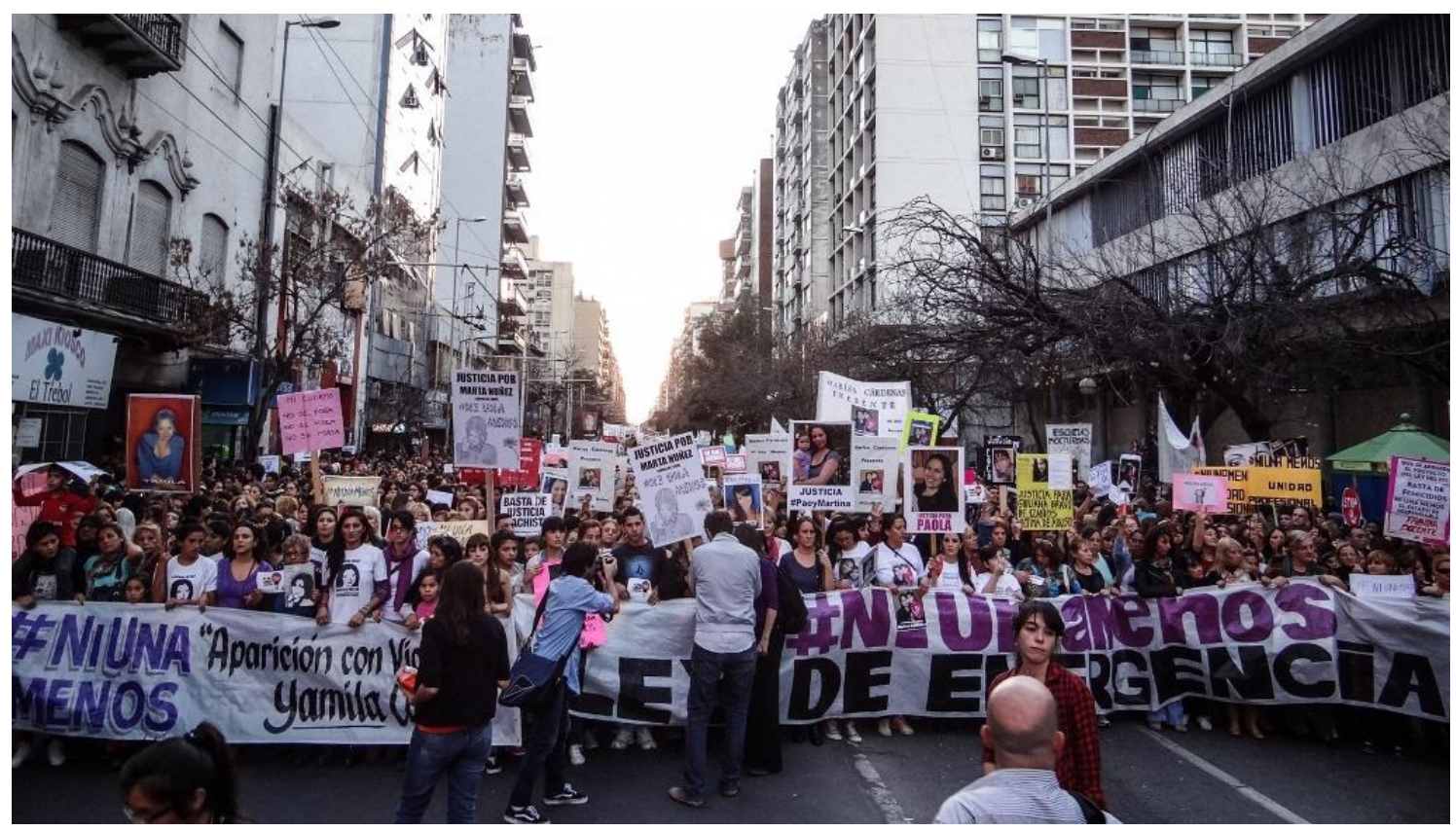

FOTOS: Irina Morán - Revista Alfilo - Periodista Feminista. Militante de Ni Una Menos Córdoba y Mujeres por un parto Respetado 


\title{
A EDUCAÇÃO E O SEU INVESTIMENTO HETERONORMATIVO CURRICULAR
}

\author{
Keith Daiani da Silva Braga ${ }^{1}$ \\ Marcio Caetano ${ }^{2}$ \\ Arilda Ines Miranda Ribeiro ${ }^{3}$
}

\begin{abstract}
Resumo: Há quem defenda que a sexualidade e o gênero não se configuram nos currículos escolares e que estas categorias não orientam as prioridades da escola. Essa afirmação nos revela duas situações iniciais: o desconhecimento das relações e práticas pedagógicas cotidianas das escolas e o conceito enrijecido de gênero e sexualidade. Historicamente, as práticas educativas, mesmo quando não verbalizadas, preocuparam-se em estabelecer, por meio de seus discursos e práticas curriculares, determinados modelos de mulheres e homens. Ao considerar este cenário, neste ensaio, balizado pelas contribuições feministas e foucaultianas, interessa-nos refletir sobre a pedagogização de gênero e da sexualidade por meio dos currículos escolares. Partimos do pressuposto que a sexualidade e o gênero não são desinteressantes às instituições de ensino, mas produzidos com caráter fortemente heteronormativo.

Palavras-chaves: Feminismo Lésbico; Escolas; Currículos.
\end{abstract}

\section{LA EDUCACIÓN Y SU INVERSIÓN HETERONICATIVO CURRICULAR}

Resumen: Hay quien defienda que la sexualidad y el género no se configuran en los currículos escolares y que estas categorías no orientan las prioridades de la escuela. Esta afirmación nos revela dos situaciones iniciales: el desconocimiento de las relaciones y prácticas pedagógicas cotidianas de las escuelas y el concepto endurecido de género y sexualidad. Históricamente, las prácticas educativas, aun cuando no verbalizadas, se preocuparon en establecer, a través de sus discursos y prácticas curriculares, determinados modelos de mujeres y hombres. Al considerar este escenario, en este ensayo, balizado por las contribuciones feministas y foucaultianas, nos interesa reflexionar sobre la pedagogización de género y de la sexualidad a través de los currículos escolares. Partimos del supuesto de que la sexualidad y el género no son desinteresados a las instituciones de enseñanza, sino producidos con carácter fuertemente heteronormativo.

Palabras claves: Feminismo lesbiano; Escuelas; Currículum Escolar.

\section{INTRODUÇÃO}

No discurso de senso comum, há quem defenda que a sexualidade não se configura nos currículos escolares e que ela não se encontra entre as prioridades da escola. Essa afirmação nos revela duas situações iniciais: o desconhecimento das relações e práticas pedagógicas cotidianas da escola e o conceito enrijecido de sexualidade. Historicamente, a sexualidade, mesmo quando não verbalizada, esteve presente nas formas como a escola estabeleceu seus discursos e orientou suas práticas pedagógicas. Poderíamos citar inúmeros casos que trazem, no fundo, as preocupações com a sexualidade. Entretanto, pensamos que nenhum caso seja mais expressivo que a

\footnotetext{
1 Mestra e doutoranda em Educação pela Faculdade de Ciências e Tecnologia da Universidade Estadual Paulista "Júlio de Mesquita Filho" FCT/UNESP. Graduada em Pedagogia pela FCT/UNESP e Professora do Instituto Federal de Educação, Ciência e Tecnologia de Goiás. Membro do NUDISE - Núcleo de Diversidade Sexual na Educação. Desenvolve estudos e se interessa por temas relacionados ao gênero e à sexualidade na educação, tais como: lesbofobia, transfobia e homofobia na escola e trajetória educacional de sujeitos não heterossexuais.

${ }^{2}$ Graduado em História pela FFP/UERJ. Mestrado e doutorado pela Universidade Federal Fluminense - UFF. Professor Adjunto no Instituto de Educação da Universidade Federal do Rio Grande - FURG.

${ }^{3}$ Doutora em História da Educação pela Universidade Estadual de Campinas - UNICAMP. Criadora e Líder do grupo NUDISE - Núcleo de Diversidade Sexual na Educação (FCT/UNESP). Durante toda a sua trajetória acadêmica, desenvolveu e orientou estudos sobre: história das mulheres, questões de gênero e educação, sexualidade e homofobia na escola. Professora titular do Programa de Pós-Graduação em Educação da Faculdade de Ciências e Tecnologia da Universidade Estadual Paulista "Júlio de Mesquita Filho" - UNESP.
} 
preocupação com a presença de mulheres e as populações lésbica, gay, bissexual, travesti e transexual nos espaços escolares. Ao considerar este cenário, neste ensaio, balizado pelas contribuições feministas e foucaultianas, interessa-nos refletir sobre a pedagogização de gênero e da sexualidade por meio dos currículos escolares. Partimos do pressuposto que a sexualidade e o gênero não são desinteressantes às instituições de ensino, mas produzidos com caráter fortemente heteronormativo.

Como parte das instituições que interagem e se integram na sociedade, a escola tem, em seu interior, sujeitos que trazem de suas relações mais amplas as aprendizagens que se configurarão, de modo desigual - dadas as relações de poder na escola - nos conhecimentos gerados com seus movimentos curriculares. Isto significa assumir que, independente das prescrições curriculares dos órgãos governamentais, a escola se caracteriza como espaço privilegiado de encontro de diversas leituras e conhecimentos do mundo. Mesmo reconhecendo a legitimidade e a força dos conteúdos curriculares prescritivos, a potencialidade e os saberes gerados através das relações constituídas nos espaços escolares serão frutos das tensões culturais de seus diversos sujeitos.

Assim, os movimentos curriculares, ainda que ausentes de reflexão, não são meras ações descritas ou magistérios neutros sem resultados práticos na vida dos sujeitos da escola. Eles são configurados por sistemas de interesses, sejam estes elaborados pelos sujeitos que estão diretamente nas práticas escolares cotidianas ou por aqueles que, na gestão curricular, orientam/determinam o que deve ser ensinado na escola. Neste sentido, reconhecendo as inúmeras instâncias socioeducativas por onde passam os sujeitos que integram as escolas e, por sua vez, os interesses implicados nos seus fazeres pedagógicos, não limitamos a formação dos movimentos curriculares à escola, ainda que seja seu espaço por excelência. Estamos entendendo como movimentos curriculares os atos escolares e as tecnologias pedagógicas (arquitetura, livros didáticos, vestimentas, mídia, etc.), que, significadas na cultura e obedecendo à certa lógica de planejamento, constroem, ensinam e regulam as performatividades, produzindo subjetividades e arquitetando formas e configurações de estar e viver na escola e, mais amplamente, na sociedade.

Assim sendo, este ensaio centra-se em debater a articulação entre a pedagogização de gênero, sexualidade e os movimentos curriculares, constituindo-se numa sugestão ao debate à academia e à educação básica, esperando-se persuadi-los/as a considerá-la em suas investigações e análises, seja para encontrar novas perspectivas, seja para confirmar ou refutar as que este ensaio lhes oferece. Para isso, o ensaio está 
organizado em três partes: na primeira, abordamos que a questão da necessidade educativa da sexualidade reside justamente em sua não naturalidade, não determinação biológica; em seguida, apresentamos as elaborações de Michel Foucault, que refutam a hipótese de que a sexualidade seja natural e selvagem, por isso reprimida, bem como apresentam a sexualidade como um dispositivo que, por meio do sexo, inscreve no corpo as práticas de poder; na última parte, expomos o gênero e seu caráter discursivo, a partir das contribuições de Judith Butler (2003; 2008), no intento de pensarmos sua regulação por meio das instituições educativas. Após, seguem-se as considerações finais e as referências bibliográficas.

\section{A NECESSIDADE EDUCATIVA DA SEXUALIDADE}

Podemos pensar de início que nosso estudo se situa no campo da educação, porque o tema escolhido, as lesbianidades, também é passível de ser problematizado nesta área. Contudo, acreditamos que, para além de uma possibilidade epistemológica, nossa problemática tem grande afinidade com a educação quando situamos que todos nós estivemos, e provavelmente ainda estaremos, durante nossas vidas, expostos a uma educação para a heterossexualidade.

Nesse sentido, sobre a relação entre a sexualidade e a educação, Monserrat Moreno (1999) nos traz uma ideia interessante:

Se os seres humanos se comportassem unicamente a partir de seus impulsos biológicos, se as condutas consideradas masculinas e femininas fossem espontâneas, naturais e predeterminadas, não seria necessário educar tão cuidadosamente todos os aspectos diferenciais; bastaria deixar que a natureza atuasse por si mesma (MORENO, 1999, p. 29).

A autora nos convoca a pensar, primeiro, que falar em termos de educação não significa nos limitarmos à ideia de escola, pois as condutas masculinas, femininas e os referenciais considerados corretos e normais de sexualidade a que ela se refere não estão circunscritos apenas à intencionalidade das instituições escolares. As intervenções e maneiras de exercitar o gênero, por exemplo, são desenvolvidas com muitíssimo empenho na família, nosso primeiro grupo social. Desta maneira, a educação familiar é uma das mais poderosas e normativas, ao lado da escola, na capacidade de interferir e de deixar marcas na vida dos sujeitos. Isso sem mencionarmos que existe a educação por meio da mídia e da religião, entre outros grupos e instituições que também fazem 
parte do processo educacional.

Para falarmos de outra maneira, se existe com maior êxito trabalhos sobre o tema, especificamente, dentro da educação escolar, isso ocorre por ser a escola por excelência um dos locais onde a educação formal ocorre, devido, em muito, a seu histórico caráter normativo. Todavia, ela não encerra nem dá conta de sintetizar a ideia de educação enquanto formação de vida.

Outro ponto que Moreno (1999) nos permite pensar é que nesse "educar tão cuidadosamente" implica nos darmos conta que, para ser educação, é necessário haver intencionalidade, um objetivo, um fim. Concordamos, assim, com Caria (1992) quando pontua a ideia de educação como a busca intencional de transformação do outro, a mudança, a alteração.

E essa transformação do outro não deve ser interpretada como puramente boa ou ruim. Semelhante à ideia de Foucault (2011) sobre o poder, em que o filósofo nos indica que o poder não é essencialmente ruim, mas, sim, produtivo, também precisamos pensar as transformações realizadas pela e na educação, não enquanto essencialmente boas ou ruins, mas, por serem intencionais, representam o desenvolvimento de um projeto de humano, de cidadão, de sujeito que se quer produzir, fabricar.

Isso nos permite refletir, por exemplo, que, quando há uma reivindicação para que haja Educação Sexual na escola, ou seja, uma proposta, um projeto, um conjunto de conhecimentos e argumentos sobre sexualidade a ser ensinado naquele espaço de forma sistemática, há uma intenção de propor o que podemos considerar "boa sexualidade", de mostrar aos alunos e alunas e construir com eles uma visão dentro daquilo que nós consideramos adequado e relevante sobre a sexualidade. Ainda que essa ideia nasça da tentativa de superar a educação sexual biologicista, heterocêntrica, excludente, ela também não será neutra, há uma tentativa de transformar e produzir sujeitos segundo uma determinada perspectiva de educação sexual, independentemente desta perspectiva se mostrar mais justa e mais igualitária que a anterior.

Assim, educar sempre implica abrir mão de qualquer ideia de neutralidade. Por mais que o ideal de sujeito a ser formado seja baseado em ideais de consensualidade, autonomia e justiça, não escapará de um modelo, de uma proposta escolhida dentre outras possíveis, um ideal (CARIA, 1992). A educação, o ato de afetar e mudar o outro não será assim, de nenhum modo, um ato desinteressado.

Então, quando nós vemos tanta gente, tantos grupos, especialmente conservadores e religiosos interessados na escola, na educação, eles estão preocupados 
com o quê? Parafraseando Berenice Bento (2011), quando uma mãe ou pai leva seu filho ou filha ao psicólogo porque não considera seu "jeito" de andar, falar e vestir adequado aos padrões de identidade de gênero e sexualidade, qual é o medo que aflige o coração deles? O que os motiva a fazer isso? O que buscam numa terapia? Podemos, com Preciado (2013), responder que é: garantir a constituição do futuro adulto heterossexual. Com isso, ao falarmos sobre gênero e sexualidade, há a enorme importância da educação: existe uma preocupação de que, por meio, especialmente, da família e da escola, as crianças e adolescentes tornem-se aquilo a que estão predestinados. Isto é, adultos alinhados aos padrões hegemônicos de identidade de gênero e sexualidade.

Assim sendo, é bastante incoerente aceitarmos muito facilmente narrativas que presumem desinteresse da escola, por exemplo, sobre os temas de gênero e sexualidade. Não é raro de se ouvir que "na escola não há espaço para discutir sexualidade", "na escola não se debate a diversidade sexual", "na escola é proibido falar de sexo", "na escola as crianças são vistas como assexuais" e "O tema de gênero não existe na escola". E é muita ingenuidade nossa crer nessas afirmações, pois a escola pode não estar interessada no que nós, pesquisadoras e pesquisadores, ativistas, militantes das diferenças, estamos discutindo sobre gênero e sexualidade, mas isso, de nenhum modo, significa que ela não tenha uma educação para a sexualidade sendo ministrada diariamente, de forma reiterada e sutil: aquilo a que alguns costumam chamar de "currículo oculto".

A escola, para citar Caetano (2016), está profundamente interessada no gênero e na sexualidade. Da sua arquitetura, passando pelos materiais didáticos e chegando às relações interpessoais, as instituições de ensino ensinam todos os dias muita coisa sobre gênero e sexualidade. Nesta mesma perspectiva, Louro (1999) argumenta que a escola está empenhada em transformar os meninos e meninas em homens e mulheres de verdade. Em outros termos, em sujeitos centrados na heteronormatividade.

Destarte, nós temos, de um lado, essa perspectiva de que, na escola, a sexualidade é tabu; e, de outro lado, a de que a escola, no fundo, é bastante empenhada em por em funcionamento a educação para a sexualidade hegemônica. Podemos perceber que essa oposição de ideias é bastante familiar. Michel Foucault é um dos autores que tem ganho, como já disse várias vezes Veiga-Neto (2011), notoriedade no campo da Educação. Apesar de não ter escrito especificamente sobre educação, os escritos do filósofo trouxeram importantes elaborações para se pensar a educação e as 
pesquisas sobre escola, principalmente seus trabalhos sobre disciplinamento dos corpos, com a obra Vigiar e Punir (1975), e sobre sexo e sexualidade, em História da Sexualidade (1976).

\section{A EDUCAÇÃO DA SEXUALIDADE}

Segundo Foucault (2004), foi a partir do século XVIII que o sexo adquiriu contorno na vida dos sujeitos, e, por meio dele, incontáveis dispositivos institucionais e discursivos objetivavam regular e controlar suas condutas e desejos. Como sequência dessa estratégia, no século XIX, o homossexualismo ${ }^{4}$ ou inversão ${ }^{5}$ foi criado pela Scientia Sexualis (FOUCAULT, 1985).

Com os estudos foucaultianos, sabemos que o alvo das regulações e controles eram, sobretudo, os corpos de mulheres. Assujeitadas, marcadas e aprisionadas, às mulheres somente restavam o conjunto de valores e regras entendidas e reconhecidas pelo modelo social androcêntrico e patriarcal. Pensar os discursos produzidos e difundidos em torno da lésbica, aproxima-nos da compreensão foucaultiana sobre os regimes de verdade, tendo como objetivo a produção da verdade última e definitiva sobre o mundo físico e social (FOUCAULT, 1993). Esses regimes são, no caso deste ensaio, as representações de estudantes que, ao estarem carregados de redes de significados, produziram performances da lesbianidade.

Para Mogrovejo (2000), o governamento de corpos e desejos de mulheres que amavam outras mulheres ocorreu, sobretudo, a partir do século XIX, quando a medicina passou de seu conhecimento sobre as enfermidades para o conhecimento daquilo que seria, "el conocimiento de las reglas de discriminación entre lo normal y lo patológico. Y en la desviación de la norma, el lesbianismo se convierte en enfermedad, que lo aísla le impone um retorno a la normalidad" (MOGROVEJO, 2000, p. 29). Essa "doença" era variável, uma vez que os diagnósticos ora a consideravam enfermidade física, ora psicológica.

Em 1869, Karl Westphald, psiquiatra de Berlim, concluiu que o "lesbianismo" era uma "anormalidade congênita, ou seja, uma má formação congênita que podia ser definida como defeito na constituição de algum órgão, ou conjunto de órgãos, que

\footnotetext{
${ }^{4} \mathrm{O}$ uso do prefixo ismo utilizado no final da palavra lesbianismo justifica-se por ser, primeiramente, dessa forma que era mencionada a lesbianidade antes da retirada do livro das doenças mentais.

${ }^{5}$ Denominação dada no período a mulheres que se relacionavam de forma afetivo-sexual com outras mulheres.
} 
determinava uma anomalia morfológica presente no nascimento" (MOGROVEJO, 2004, p.12). Ainda segundo a autora, alguns anos mais tarde, em 1887, Paul Moreau utilizou o termo "aberração" para definir a inversão, considerando-a, ainda, como um vício vergonhoso que a antiga Lesbos havia deixado às sociedades modernas. As relações carnais entre mulheres, esses amores insensatos que alguns autores modernos tiveram dificuldade de descrever em decorrência de sua perspectiva falocêntrica da relação sexual, poderiam se revestir de um caráter patológico ou dar lugar a um autêntico delírio parcial limitado ao genital. Anteriormente a essa afirmativa de Moreau, Richard Kraff-Ebing, em 1886, já havia apresentado argumentos sobre a doença. Segundo ele, a inversão era uma psicopatia sexual, que podia ser advinda de duas formas: inata ou adquirida. $\mathrm{O}$ teórico, ao significar a psicopatia, recomendava às famílias uma maior atenção para com as filhas e/ou entes femininas. Ele advertia, ainda, que o "lesbianismo" era um mal perverso que se opunha aos objetivos da natureza, ou seja, não objetiva a procriação.

Segundo Mogrovejo (2004), os discursos produzidos sobre a lesbianidade foram elaborados e interpelados por marcas sociais que buscavam "esquadrilhá-la" por meio da linguagem e das instâncias educativas. Esse quadro vai de encontro ao entendimento com as afirmações de Lauretis (2000), para quem ser lésbica é uma ação de liberdade, considerando que nenhum destino sexual governa a vida dos indivíduos. Contudo, não podemos negar a força com que as instâncias educativas heteronormativas atravessam os sujeitos, ao ponto de que a heterossexualidade seja a única alternativa de viver a sexualidade e projetar socialmente o gênero.

As considerações feitas até aqui nos auxiliam a refletir sobre os aportes e debates acerca de Foucault e da ação educativa. O autor torna-se importante para compreender como a educação passa a ser uma forma tão poderosa de moldar os corpos, tanto em seus gestos como em suas utilidades. Explica-nos que, a partir dos séculos XV e XVI, o Ocidente passa a se preocupar com a educação, não somente clerical, mas daqueles que viriam a se tornar comerciantes, homens da lei, entre outros. Inicia-se uma perspectiva de educar, formar as crianças desde pequenas. A educação, então burguesa, se tornará, a partir desse período, bastante popular, porque esse processo está inserido nos fenômenos da disciplinarização da sociedade ocidental (CASTRO, 2009).

Nesse processo de disciplinarização da educação, Foucault irá enfatizar a nova importância que a questão do corpo ganhará (CASTRO, 2009), em suas palavras, “[...] 
a partir da Revolução Francesa, um dos objetivos prescritos ao ensino primário será fortificar e desenvolver o corpo" (FOUCAULT, 2011, p. 212).

O corpo, neste contexto, é entendido como o lugar em que atua aquilo que o filósofo chamou de poder disciplinar, isto é, um tipo muito específico de poder que opera em último nível; é a forma pela qual o poder político e todos os poderes em geral podem chegar a tocar os corpos, tomar conta dos gestos, comportamentos, das palavras, hábitos. Em resumo, “[...] el poder disciplinario es una modalidad determinada, muy específica de nuestra sociedad, lo que podríamos denominar contacto sináptico cuerpopoder" (FOUCAULT, 2005, p. 59-60).

A partir das teorizações foucaultianas, por ser o sexo essencialmente corporal, existe seu controle (disciplinamento) no nível do corpo individual, não apenas ao que se diz respeito ao controle da vida em termos de população (biopoder); e a educação, nosso campo de interesse, tem uma relação histórica de estreitamento com as práticas de disciplinarização do corpo, marcadas pelo gênero e pela sexualidade.

A sexualidade, pensada em correntes tradicionais, enquanto aspecto natural dos humanos que foram, a partir do período vitoriano, reprimidos nas sociedades ocidentais por meio de tabus e proibições, foi o argumento mais rebatido por Michel Foucault (1985) em História da Sexualidade. Para ele, a sexualidade não é uma derivação ou extensão da biologia, mas uma construção social, cultural, histórica e discursiva, como também não foi reprimida, mas colocada, principalmente nos séculos XVIII e XIX, de forma insistente nos discursos. Incitada, estimulada e proliferada, tornou-se um dispositivo, que, ao fixar, pela reiteração, o sexo como eixo central da existência, inscreve no corpo as práticas de poder, regulação e normalização dos sujeitos (FOUCAULT, 1985; SCAVONE, 2006; SWAIN, 2006; SPARGO, 2006).

Em síntese, com Foucault (1985) refutando a hipótese repressiva, ganharam fôlego essas elaborações de que dispomos hoje para pensar que a sexualidade não é tabu na escola, não é reprimida, pelo contrário, ela é estimulada, produzida, tutelada para atender aos parâmetros do que é considerado "normal", disfarçada de natural, de espontânea e autônoma. Foucault, para ampliar tal compreensão, identificou quatro dispositivos que nos permitem compreender a sexualidade como o produto de tecnologias positivas e produtivas, e não como o resultado negativo de tabus, repressões e proibições legais. Estas quatro grandes tecnologias da sexualidade são: a histerização do corpo da mulher, a pedagogização do sexo da criança, a socialização das condutas procriadoras e a psiquiatrização do prazer perverso (PRECIADO, 2002). 
A respeito da histerização do corpo da mulher, o feminino passa a ser concebido como saturado de sexualidade, e, com isso, incorporado às práticas médicas, que devem controlá-lo, guiá-lo, regulá-lo, prescrever-lhe regras de conduta etc. Com isso, tornou-se possível que, por um lado, houvesse uma comunicação [...] "orgânica com o corpo social, o espaço familiar e a vida dos filhos" (CASTRO, 2009, p. 400), haja vista que as mulheres cuidavam dos corpos e da educação das crianças; por outro, que se instituísse um modo de perceber o sexo de três modos: algo que é do homem e da mulher, mas que é de pertencimento do homem e constitutivo do próprio corpo da mulher (CASTRO, 2009).

Alinhando essa argumentação com nosso estudo, podemos compreender o porquê de, quando falamos de lesbianidade, não podermos esquecer de abordar a questão de que as mulheres ainda possuem sua sexualidade tomada discursivamente como propriedade dos homens (LAURETIS, 1994), fato que justifica a proposital indiferença existente na história das mulheres não heterossexuais. $\mathrm{O}$ silenciamento imposto às histórias lesbianas figura a hostilidade em se aceitar a existência de vidas femininas não centradas em falos.

Adiante, Foucault (1985) nos fornece teorizações a respeito da pedagogização do sexo infantil, que foi tomada por meio da rejeição a práticas sexuais - como a masturbação - que passavam a ser vistas como perigos gravíssimos para as crianças, que tenderiam a crescer na imoralidade, colocando em risco, inclusive, seu desenvolvimento físico. Deste modo, as crianças são vistas como seres com corpos que possuem sexo somente na anatomia (órgãos genitais), mas ausente de atividade sexual. Cabendo, por fim, aos pais, médicos e pedagogos a responsabilidade de vigiar e cuidar desses corpos infantis para que não pratiquem as atividades perigosas.

É na socialização das condutas procriadoras que se inicia uma política de incentivo ou de restrição à reprodução; os casais são incitados à fecundação, já aos médicos e à ciência, cabe a incumbência de controlar os nascimentos (FOUCAULT, 1985; CASTRO, 2009). Em específico, há, a seguir, uma operação e controle da vida, em termos de população.

Por fim, no que tange à psiquiatrização dos prazeres perversos: "o instinto sexual foi isolado como um instinto biológico e psíquico autônomo, as suas anômalas foram clinicamente analisadas, as condutas foram normalizadas e patologizadas" (CASTRO, 2009, p. 400). Deste modo, o sexo passa a se referir a funções biológicas, justificadas e entendidas a partir de suas características anatômicas fisiológicas. Mas o 
instinto sexual pode se desviar, apresentando, assim, condutas pervertidas (FOUCAULT, 1985; CASTRO, 2009).

Em síntese, as elaborações foucaultianas corroboram que a sexualidade, a partir do século XIX, é analisada, conferida, esmiuçada e investigada, com tanto empenho e atenção que, suspeitando de todo e qualquer detalhe, examina-se a todos, inclusive acompanha-se sua manifestação nos primeiros anos de vida das crianças, no corpo das mulheres, nas condutas tidas como estranhas. Em síntese, o sexo toma, então, a centralidade da política. Isso em muito se deve porque o sexo se encontra na ligação entre dois eixos, por meio dos quais longamente se aplicou toda uma tecnologia de vida. Residem em um eixo as disciplinas do corpo: docilização, distribuição no espaço, articulação das forças e economia das energias. No outro eixo, o controle das populações, por meio das incitações ou limitações à procriação, o controle estatístico de nascimentos e a socialização de campanhas ideológicas para moralizar os sujeitos, dentre outros mecanismos (FOUCAULT, 1985; CASTRO, 2009). Podemos, então, sintetizar que as estratégias de controle e incitação supracitadas não se trata de formas de barrar o sexo ou de impedir a sexualidade, pelo contrário. Trata-se de articular o sexo, organizá-lo e produzi-lo.

\section{A RESPEITO DO GÊNERO}

Seguindo essa mesma linha, a filósofa norte-americana Judith Butler (2003) desloca a síntese de Foucault (1976) sobre a construção da sexualidade nos discursos para pensar o gênero também com caráter discursivo (SPARGO, 2006). Em sua perspectiva, o gênero não é algo que nos pertence, conjunto de atributos masculinos e femininos que possuímos, mas, sim, performativo, o efeito dos atos e estilizações repetidas do corpo, que realizamos durante toda a vida, e que, por sua repetição, possui verniz de naturalidade (BUTLER, 2003).

É importante destacar que a desnaturalização do gênero já havia se iniciado com autoras feministas a exemplo de Simone de Beauvoir, na década de 1940, e Betty Friedan, na década de 1960, e desenvolvido nas décadas seguintes por diversas feministas, tais como Gayle Rubin (1975), Monique Wittig (1980), Adriane Rich (1980) e Joan Scott (1995 [1986]). O que trazemos de Butler, originalmente publicadas nos anos 1990, nos EUA, são as considerações em torno do poder da linguagem e do discurso, para pensar o caráter performativo do gênero. 
Butler vai trazer a ideia de que a reiteração cria o gênero. Reiterar significa que é através da repetição de práticas e de atos que o gênero existe. O gênero se faz na ação, através das roupas, adereços, gestos, olhares, modos de falar, andar, comportar, ou seja, toda uma estilística considerada apropriada, correta (BUTLER, 2003; BENTO, 2011). E mais, tal ação ininterrupta é negociada socialmente. Assim, determinadas performatizacões são aceitas, enquanto outras são questionadas e, até mesmo, rejeitadas.

A origem desta teoria, deste "fazer" o gênero é, em grande parte, assentada no pensamento desenvolvido por Beauvoir em sua obra $O$ segundo sexo. Especificamente, a reflexão "Ninguém nasce mulher: torna-se mulher" motivou Butler (2003) a pensar no gênero como um eterno tornar-se, um eterno fazer-se.

Nós, nessa lógica, nunca chegamos a ser o gênero, mas fazemos o gênero. Dentro de uma prática discursiva contínua, gênero é um processo. Dito de outro modo, é algo que nós fazemos e não algo que somos (SALIH, 2012). Isso implica afastar qualquer ideia de naturalidade no gênero. Pelo contrário, leva-nos a pensar na construção, na artificialidade do gênero.

Neste sentido, Butler irá, sobretudo, refutar a ideia de que sexo e gênero são distintos. Para ela, “[...] por definição, o sexo se revelará ter sido o gênero o tempo todo" (BUTLER, 2003, p.08). A autora desfaz essa distinção sexo/gênero para argumentar que não há sexo que não seja já e, desde sempre, gênero. Todos os corpos são "generificados" desde o começo de sua existência social (e não há existência que não seja social), o que significa que não há "corpo natural" que preexista à sua inscrição cultural.

Quando eu falo corpo, eu já trago toda a significação cultural que essa palavra possui. Assim, quando penso em "sexo", não estou pensando em algo que não seja gênero. A ideia de sexo possui embutida em si mesma o gênero. Não seria possível, na perspectiva butleriana, olhar para o "sexo" sem o gênero.

Acrescenta, ainda, que o interessante seria buscar, por meio de uma pesquisa genealógica, identificar de que modo e através de quais discursos o sexo e o gênero foram instituídos enquanto "dados", e, em especial, como foi construída e fabricada discursivamente essa dualidade. Desta maneira, o gênero não deveria mais ser considerado como inscrição cultural de um sexo autônomo. Mas precisaria ser compreendido como o meio discursivo e cultural através do qual o sexo é tanto produzido quanto afirmado como pré-discursivo (PISCITELLI, 2002). 
Outro aspecto, dentro do conceito de gênero e de grande relevância para nossa pesquisa, é a ideia da performatividade. Quando Butler propõe que o gênero é performativo, quer dizer que ele é um fazer, porém, não um fazer por um sujeito que preexista ao feito (BUTLER, 2003). A filósofa se apoia na premissa da existência de uma ação contínua, sem um ator que a empenhe. Assim, ela inverte o pensamento e nos traz a possibilidade da existência de um ator que se constrói nessa ação, que é efeito dela.

Para compreendermos melhor tal argumento, precisamos diferenciar performance de performatividade, ainda que, como aponta Salih (2012), esses termos sejam, em alguns momentos, usados por Butler (2003) de forma indistinta em "Problemas de Gênero". Performance pressupõe um sujeito, ator, que se apresenta, como em uma peça teatral, alguém que "empresta" seu corpo aos contornos e características de um personagem. Com performatividade, Butler propõe que o gênero é um ato que faz existir aquilo que ele nomeia. Logo, as identidades de gênero são construídas e constituídas na linguagem, o que significa que não há identidade de gênero "anterior" à linguagem (SALIH, 2012; BUTLER, 2003). Em resumo, poderíamos dizer que não é que a identidade "faça" o gênero, como em uma performance, mas, sim, que as identidades são efeitos do gênero.

Tudo isso se dá na superfície dos corpos. O gênero é uma fabricação inscrita nos corpos, um estilo corporal, inclusive não se adquire de uma vez, quando se nasce, por exemplo, mas se realiza por toda a vida. Isso significa dizer que, em inúmeros momentos durante nossa existência social, estamos sujeitos às avaliações e regulações das normas de gênero: o nosso corte de cabelo, nossa roupa, a forma com que empossamos a voz, nossas decisões profissionais, nossa maneira de caminhar, sujeitos com quem vivenciamos nossos desejos, nossas atitudes mais íntimas e sutis. Tudo se amarra - algumas mais outras menos - à nossa performatização de gênero.

Assim, ao retomarmos as primeiras pontuações que trouxemos inicialmente a respeito da necessidade da educação, quando falamos de gênero e sexualidade, juntamente com a citação da autora Monsserat Moreno (1999), recolocamos aqui a pergunta: se o gênero fosse realmente espontâneo e natural, como pregam diversas teorias biologicistas, demandaria de tanto esforço e repetição para se produzir?

Desde que nascemos, desde a mais tenra idade, é-nos ensinado - por diversos discursos e instituições educativas, em especial a familiar e a escola - o respeito à lógica sexo-gênero-desejo, que, em síntese, refere-se à correspondência rígida e binária 
estabelecida entre sexo biológico (cromossomo $\mathrm{XX}, \mathrm{XY}$ ), identidade de gênero (masculino/feminino) e desejo (homossexual/heterossexual), de modo a dar coerência e naturalidade à heterossexualidade. A partir disso, sempre somos impelidos a performatizar nosso gênero "de acordo" com nosso "sexo" e a nos atrairmos erótico, sexual e afetivamente por nossos "opostos".

Dito de outro modo, uma criança, ao nascer, já se encontra imersa em um meio linguístico-discursivo que a submete a apenas duas possibilidades (macho/fêmea), opostas e hierarquizadas - prévia e ficcionalmente construídas. No caso, por exemplo, da heterodesignação ${ }^{6}$ biologicista determinar "fêmea", a sentença médica "é uma menina", será lançada e inaugurará o processo ininterrupto de aquisição do gênero, que cobrará desse novo "ser" encarnações específicas de feminilidade, com o intento de, futuramente, complementar outro sujeito heterodesignado homem e constituído forçosamente na masculinidade. $\mathrm{O}$ encontro dos dois, simbolizado com frequência no segundo grande ato performativo, "os declaro marido e mulher"; é então entendido e propagandeado como a união perfeita, coerente e natural, em detrimento de outras formas de arranjos (BUTLER, 2003; 2008).

A questão que nos importa, a partir dessas considerações teóricas, é a seguinte: toda essa produção de corpos centrados na heterossexualidade demanda um esforço excessivo e contínuo para se sustentar. E é nesse sentido que a infância - etapa central para os primeiros exercícios de gênero - é vista como garantia de constituição do adulto, previsto nos moldes de identidade e sexualidade hegemônicos (PRECIADO, 2013).

A escola, antecipada pela família, historicamente, por seu caráter normativo e disciplinar (FOUCAULT, 1976), combinado com sua tutela parcial de crianças e adolescentes, torna-se um dos espaços institucionais mais poderosos na reiteração e naturalização desses preceitos (MORENO, 1999; LOURO, 1997; BENTO, 2011).

No seio da família, todo um projeto se inicia para a chegada de um novo ser, com gênero já heterodesignado pela ciência médica. A cor das roupas, os brinquedos, o nome, as projeções futuras, a personalidade, o conjunto de atributos qualitativos, tudo

6 Retomamos e ressignificamos a categoria heterodesignação hegemônica (heterodesignación hegemónica) elaborada por Magda Rodríguez (1994a) em que a descreve como a "definición del otro por parte de quien tiene el poder de la palabra (p. 220)". A autora define o grupo ou saber hegemônico como o detentor do poder de definir o outro e ao grupo heterodesignado. Em relação ao conceito de diferença, a autora expressa: "lo diferente entra dentro de las estrategias de domínio, de la exclusión/ integración y como zona heterodesignativa, definida por parte del grupo hegemónico (detentor do poder/saber) que, al definirse como uno, autónomo e idéntico, há de separar de su seno todo lo diferente" (1994b. p. 96-97). 
se decide antes da chegada da criança. As primeiras palavras ditas, as preferências, as brincadeiras, os lugares permitidos, os lugares proibidos, as formas de usar o próprio corpo, as relações mãe-criança, pai-criança, os adjetivos, as condutas estimuladas, os comportamentos coibidos, uma educação para o gênero adequado é especialmente investida e empenhada no âmbito familiar.

Ao lado, na escola, temos: divisão de banheiros por sexo biológico (XX, XY); uso de linguagem androcêntrica - ainda que a maioria dos sujeitos seja indiscutivelmente feminina -, a qual perpetua a ocultação e o lugar de menor prestígio das mulheres; crença e circulação de diversos discursos que naturalizam características comportamentais tidas como de meninos e meninas; conteúdos, exercícios, contos, histórias e materiais que tomam a heterossexualidade como única relação possível (SABAT, 2003; FURLANI, 2008). Avaliações e relações docentes-estudantes atravessadas de variados aspectos subjetivos, tais como letra "caprichada", caderno limpo e enfeitado, obediência, delicadeza, entre outros estreitamente ligados ao ideal de feminilidade, para com alunas. O contrário se observa com relação aos alunos. Em síntese, parafraseando Bujes (2002), na escola, opera toda uma maquinária da infância no auxílio de produção das feminilidades e masculinidades heterossexuais.

\section{CONSIDERAÇÕES FINAIS}

Buscamos, ao longo do texto, por meio de levantamento bibliográfico desenvolvido em nossa pesquisa sobre lesbianidades e trajetórias escolares, expor que a sexualidade não é tema desprezado pelas instituições de ensino. Ainda que, no espaço de muitas famílias, escolas, igrejas e outros ambientes educativos não haja uma visão da temática na mesma direção que nós - educadoras e educadores alinhados aos debates feministas, de direitos humanos e/ou da Teoria Queer -, isso não significa que não exista uma intencionalidade educativa direcionada às crianças e aos adolescentes, em termos de garantia da heterossexualidade.

Em outras palavras, argumentamos que os sujeitos, ao longo de suas vidas, têm seus corpos investidos de normas regulatórias de gênero e são expostos a uma espécie de pedagogização da sexualidade de forma heteronormativa. Todavia, é importante ressaltar que há corpos que resistem, não se conformam e escapam, ao menos em partes, deste investimento. Temos então: estudantes lésbicas, travestis, transexuais, gays, bissexuais, entre tantas outras possibilidades de sujeitos não heterossexuais 
tencionando o espaço, as representações, o currículo e as relações sociais educativas.

Estudar os relatos desses sujeitos permite, no sentido de relevância científica, uma problematização dentro do campo da Educação acerca das tensões, rupturas, estratégias e readequações, construídas e reconstruídas nas instituições de ensino a fim de lidar com a diferença, quando essa deixa de ser inteligível ou se mostra contrária/transgressora ao plano educacional de meninos e meninas nos moldes hegemônicos de identidade de gênero e sexualidade.

\section{REFERÊNCIAS}

AUAD, D. Educar meninas e meninos: relações de gênero na escola. São Paulo: Contexto, 2006.

BENTO, B. Na escola se aprende que a diferença faz a diferença. Estudos Feministas, Florianópolis, v. 19, n. 2. 2011, p. 549-559.

BUJES, M. I. E. Infância e maquinarias. Rio de Janeiro: DP\&A, 2002.

BUTLER, J. Cuerpos que importan: Sobre los limites materiales y discursivos del "sexo". 2 ed. Buenos Aires: Paidós, 2008 [1993].

BUTLER, J. Problemas de Gênero: feminismo e subversão da identidade. Rio de Janeiro: Civilização Brasileira, 2003 [1990].

CAETANO, M. Performatividades Reguladas: heteronormatividade, narrativas biográficas e educação. Curitiba: Appris, 2016.

CARIA, Perspectiva sociológica sobre o conceito de educação e a diversidade das pedagogias. In: Sociologia - Problemas e Práticas, n. ${ }^{\circ}$ 12, pp. 171-184, 1992.

CASTRO, E. Vocabulário de Foucault: um percurso pelos seus temas, conceitos e autores. Belo Horizonte: Autêntica, 2009.

FOUCAULT, M. El poder psiquiátrico. Vol. 245. Cidade: Ediciones AKAL, 2005.

FOUCAULT, M. A ética do cuidado de si como prática da liberdade. In: Ditos e Escritos V. Ética, sexualidade e política, por Michel Foucault. Rio de Janeiro: Forense Universitária, 2004. P. 264-287.

FOUCAULT, M. Verdade e Subjetividade. Revista de Comunicação e Linguagens. Lisboa: Edições Cosmos, n. 19, dez., 1993, p. 203-223.

FOUCAULT, M. História da sexualidade I: a vontade de saber. 8 ed. Rio de Janeiro: Graal, 1985 [1976].

FOUCAULT, M. Vigiar e punir: nascimento da prisão. 39 ed. Petrópolis, RJ: Vozes. 
2011 [1975].

FURLANI, J. Mulheres só fazem amor com homens? A educação sexual e os relacionamentos entre pessoas do mesmo sexo. Revista Proposições, Santa Catarina, v. 19, n. 2(56), maio/ago. 2008, p. 111-131.

LAURETIS, T. A tecnologia de gênero. In: HOLLANDA, H. (Org.). Tendências e impasses: o feminismo como crítica da cultura. Rio de Janeiro: Rocco, 1994. p. $206-$ 242.

LAURETIS, T. Sujetos excéntricos. La teoría feminista y la conciencia histórica. In. Diferencias: etapas de un camino a través del feminismo. Madrid, Horas y horas. Cuadernos inacabados, n.35, 2000.

LOURO, G. Gênero, sexualidade e educação: uma perspectiva pós-estruturalista. Petrópolis: Vozes, 1997.

LOURO, G. Pedagogias da sexualidade. LOURO, G. L.(org.), O Corpo educado: pedagogias da sexualidade. Belo Horizonte: Autêntica, 1999. p. 07-34.

MOGROVEJO, N. A. Teoria lésbica, participación política y literatura. Ciudad de México: Universidad de la Ciudad de México, 2004.

MOGROVEJO, N. A. Um amor que se atrevió a decirsunombre: La lucha de las lesbianas y surelación com los movimentos homosexual y feminista em América Latina. México: Plaza y Valdes, 2000.

MORENO, M. Como se ensina a ser menina: o sexismo na escola. São Paulo: Moderna; Campinas: Editora da Universidade Estadual de Campinas, 1999.

PRECIADO, B. Manifesto contra-sexual: prácticas subversivas de identidad sexual. Madrid: Pensamiento Opera Prima, 2002.

PRECIADO, B. Quem defende a criança queer?. Texto traduzido por Fernanda Nogueira e originalmente publicado sob o título "Qui défend l'enfant queer?" em: http://www.liberation.fr/societe/2013/01/14/qui-defend-1-enfant-queer_873947. 2013. Disponível em: http://espacosqueer.blogspot.com.br/p/inscricoes.html. Acesso em: 11 out. 2013.

PISCITELLI, Adriana. Recriando a (categoria) mulher? In: ALGRANTI, L. (Org.). A prática feminista e o conceito de gênero. Textos Didáticos, n. 48. Campinas:

IFCH/Unicamp, 2002, p. 7-42.

RODRÍGUEZ, M. El feminismo francés de la diferencia. AMORÓS, Celia. In Historia de la teoría feminista. Madrid/ES: Instituto de Investigaciones Feministas de la Universidad Complutense de Madrid/Consejería de Presidencia, Dirección General de la Mujer, 1994a.

SABAT, R. Filmes infantis e a produção performativa da heterossexualidade. Tese (Doutorado em Educação) - Faculdade de Educação, Universidade Federal do Rio 
Grande do Sul, Porto Alegre, 2003.

SALIH, S. Judith Butler e a Teoria Queer. Belo Horizonte: Autêntica, 2012.

SCAVONE, L. O feminismo e Michel Foucault: afinidades eletivas?. In: SCAVONE, L.; ALVAREZ, M. C.; MISKOLCI, R. (Orgs.). O legado de Foucault. São Paulo: EDUNESP/FAPESP, 2006. p. 81-99.

SPARGO, T. Foucault e a Teoria Queer. Rio de Janeiro: Pazulin; Juiz de Fora: Editora UFJF, 2006.

SWAIN, T. N. A desconstrução das evidências: perspectivas feministas e foucaultianas. In: SCAVONE, L.; ALVAREZ, M. C.; MISKOLCI, R. (Orgs.). O legado de Foucault. São Paulo: EDUNESP/FAPESP, 2006. p. 119-137.

VEIGA-NETO, A. Foucault \& a educação. 3 ed. Belo Horizonte: Autêntica, 2011. 